\title{
Schreiben des französischen Syndicat de la Magistrature* zu den Disziplinar- und Strafverfahren gegen politische Verteidiger in der Bundesrepublik
}

Syndicat de la Magistrature

Paris, den 4. Februar 1977

4, Rue Olier, 750 rs Paris

An den Herrn Bundeskanzler

der Bundesrepublik Deutschland [...]

An den Herrn Bundesminister

für Justiz [...]

Sehr geehrter Herr Minister,

Das "Syndicat de la Magistrature «, das ein Viertel der französischen Richter und Staatsanwälte umfaßt, hält es für wichtig, Ihnen seine Beunruhigung auszudrücken über die sich in der Bundesrepublik Deutschland vermehrenden Disziplinar- und Strafverfahren, gerichtet gegen Anwälte, die die Verteidigung politischer Häftlinge unternehmen wollten.

Wir haben nicht Partei zu ergreifen, was die Anschuldigungen, die Klienten dieser Anwälte betreffend, anbelangt; der Gegenstand unseres Briefes ist keineswegs, uns auszusprechen über die Berechtigung oder Unberechtigung der Tatbestände, die diese Anschuldigungen und Verhaftungen verursacht haben; es steht uns auch nicht zu, ausfindig zu machen, ob diese oder jene Handlung, die sie unternommen haben, gegebenenfalls eine Bedrohung für die Sicherheit des deutschen Staates darstellt.

Wir sind jedoch, so scheint es uns, in unserer Eigenschaft als Richter und Staatsanwälte und Gewerkschaftler, die jeden Tag Männer und Frauen, angeklagt wegen Tatbeständen, die politische oder individuelle Begründungen haben, anklagen, richten und verurteilen, berufen zu sagen, was wir über die Rolle des Rechtsanwaltes im Prozeß denken und unsere Beunruhigung auszudrücken, wenn uns die Rechte der Verteidigung in der Justiz eingeschränkt zu sein, um nicht zu sagen, verspottet zu werden scheinen.

Die Suspensionsmaßnahmen, die Disziplinar- und Strafverfahren, die kürzlich gegen mehr als 40 Anwälte unternommen worden sind, und insbesondere das Verfahren eingeleitet gegen den Rechtsanwalt Kurt Groenewold beim Berufungsgericht in Hamburg, begleitet von einem starken Pressefeldzug, stellen Maßnahmen dar, die keine Präzedens haben in den demokratischen Ländern Europas.

Unser Erstaunen vergrößert sich noch bei der Lektüre der Hauptanklagepunkte gegen Herrn Groenewold: Unterstützung des Hungerstreiks seiner Klienten durch "Rundschreiben « betreffend die Verteidigung, Organisation eines Informationssystems zwischen Häftlingen.

Es ist unbestreitbar, daß die deutsche Gesetzgebung, die hält auf die Meinungsfreiheit, die Ausdrucksfreiheit und die Freiheit des Zugangs zur Information, den Meinungsaustausch der Häftlinge untereinander erlaubt und ebenso deren Zugang

\footnotetext{
" Richtergewerkschaft, der ca. $2 \% \%$ aller Richter und Staatsanwälte in Frankreich angehören. Zum Syndicat de la Magistrature vgl. die Beiträge von U. Reifner und H. Bäumer, in: KJ 1976 S. 258 u. S. 278 (Anm. Red. KJ).
} 
zu den gedruckten Informationsmitteln (Zeitungen, Bücher usw.), wie auch Berichte über die Lebensbedingungen der Gefangenen.

Angesichts eines Pressefeldzuges, der darauf hinzielte, die politischen Häftlinge von der öffentlichen Meinung und vor jeglichem Urteil zu verurteilen, war es die Pflicht der Anwälte, derselben öffentlichen Meinung die unerträglichen Haftbedingungen ihrer körperlich und seelisch geschwächten Klienten klar aufzuzeigen, und dieser die Gründe des Hungerstreiks dieser Häftlinge zu erklären.

Den Anwälten mußte es ebenfalls freistehen, mit ihren Klienten deren Verteidigungssystem zu organisieren und eine kollektive Verteidigung einer individuellen Verteidigung vorzuziehen, da letztere dem politischen und kollektiven Wesen der Taten, die ihren Klienten zur Last gelegt worden sind, nicht Rechnung getragen hätte, und die kollekrive Verteidigung besser ihren Ansprüchen entsprach.

Diese Tatbestände alleine sind nicht strafbar, denn sie gehören zu den traditionellen Rechten der Verteidigung; es handelt sich um Verteidigungsmittel, die laufend in unseren Ländern angewendet werden. Man gibt vor, in den Absichten, die man den Anwälten unterschiebt, den strafbaren Charakter der ihnen vorgeworfenen Tatsachen zu finden. Lediglich der Tatbestand der Bekanntmachung der Gründe eines Hungerstreiks und die Organisation einer kollektiven Verteidigung wird kriminalisiert, weil er ermöglichen kann, daß die kriminelle Vereinigung auch im Gefängnis bestehen bleibt, und weil er geeignet ist, die von den Häftlingen verfolgten Ziele zu unterstützen.

Es handelt sich dann darum, mehr als ein Absichtsvergehen zu bestrafen, ein auf Zufall beruhendes Verbrechen, das seine Bestandteile nur in Vermutungen von Eventualitäten findet und das nicht auf genau festgestellten Tatsachen beruht.

Wie lächerlich auch das gegen Herrn Groenewold und seine Amtsbrüder eingeleitete Verfahren sein mag, ist es dennoch nicht weniger beunruhigend, wegen dem, was es von der seit einigen Jahren stattfindenden Entwicklung der deutschen Gesetzesgebung aufdeckt.

Die zwei Reformen der Strafprozeßordnung von den Jahren 1950 und 1965 hatten die Gesetze von den Abänderungen, welche unter dem nationalsozialistischen Regime gemacht worden waren, befreit und hatten die Rechte des Angeklagten und der Verteidigung verbessert, unter dem Einfluß der Gesetze, die in den demokratischen Ländern in Kraft sind.

Die neuen Strafgesetze und Strafprozeßordnung und insbesondere die zwei im Jahre 1975 in Kraft getretenen Gesetze scheinen uns der gegenteiligen Entwicklung zu folgen.

Das erstere, das die Macht der Polizei und der Staatsanwaltschaft vergrößert auf Kosten der Richter, bringt eine Verstärkung der Macht des Staates und sichert der politischen Macht einen größeren Einfluß zu auf die Justiz.

Das zweite, das es vervollständigt, greift die Stellung der Verteidigung im Prozeß an, stellt in Frage die Ausdrucksfreiheit des Anwaltes und verbietet die Organisation einer kollektiven und politischen Verteidigung.

Einem Verbrecher, politischer oder strafrechtlicher Art, und was auch die Schwere seines Verbrechens sein mag, das Recht abzustreiten, die Anwendung der demokratischen Gesetze und die Beachtung der grundsätzlichen Rechte der Verteidigung zu fordern, bedeutet Anerkennung der Willkür und bestätigt die Verneinung der Demokratie selbst.

Die Respektierung des Grundgesetzes darf eine derartige Konsequenz nicht haben.

Die Situation des Herrn Groenewold und der anderen angeklagten Anwälte erinnert an die Verfahren gegen mehrere Anwälte im Jahre 196I vor den strafrechtlichen 
Instanzen in Frankreich, weil diese, unter ähnlichen Bedingungen, algerische politische Angeklagte verteidigt hatten; so ist es wahr, daß kein Land geschützt ist vor einer Rückkehr zu autoritären Methoden, die die Freiheit einschränken.

Französische und ausländische Stimmen, vor allem deutsche, hatten sich dann erhoben, um gegen diese Verfahren zu protestieren, die die Rechte der Verteidigung verletzen.

Der Respekt der Freiheiten hatte dann gesiegt und die Anwälte waren freigesprochen worden.

Auch bleibt das Syndicat de la Magistrature, das für die Rechtsprechung, gleich ob politischer oder strafrechtlicher Art, eine Verteidigung, die die Freiheit der Organisation hat und die Wahl der Mittel und Worte als wesentlich betrachtet, aufmerksam angesichts der Entwicklung der Situation in Deutschland, was die demokratischen Rechte und Freiheiten anbelangt, sowie das Schicksal, das die Anwälte erwartet.

Wir verbleiben, sehr geehrter Herr Minister, mit vorzüglicher Hochachtung

Le Bureau National du Syndicat de la Magistrature

gez.

H. Guemann

\section{Detlef Horster}

Bloch zur Einführung

mit einem Vorwort von 0 . Negt und 15 Bildern aus dem Leben Ernst Blochs.

Broschur, 80 Seiten, 5,- DM

Dieses Buch soll vor allem die Aufgabe erfüllen, dem Leser den Zugang zum Studium der Bloch-Werke zu erleichtern, so daß nach der Lektüre mit jedem Band aus den Werken von Bloch, dem Autor von "Naturrecht und menschlicheWürde" begonnen werden kann. ....Diese Schrift ist nicht nur eine gute Einführung in Bloch, sondern eine gelungene Hinführung des philosophisch Interessierten zur marxistischen Philosophie insgesamt." (aus dem Vorwort von Oskar Negt)

SOAK Verlag 3000 Hannover 1, Am Taubenfelde 30

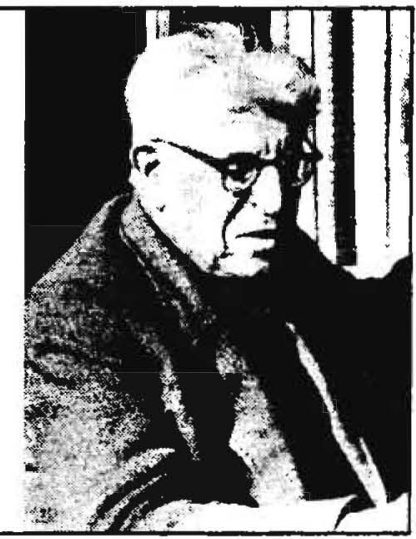

